\title{
Presenteeism among Chinese workers in Japan and its relationship with mental health and health- promoting lifestyles
}

\author{
Weng LI ${ }^{1 *}$, Michiko MORIYAMA ${ }^{1}$, Ying'ai CUI ${ }^{1}$, Kana KAZAWA ${ }^{1}$, \\ Takashi NAKAYA ${ }^{2}$ and Tantut SUSANTO ${ }^{3}$ \\ ${ }^{1}$ Department of Chronic Care and Family Nursing, Graduate School of Biomedical and \\ Health Sciences, Hiroshima University, Japan \\ ${ }^{2}$ Program in Health and Welfare, Graduate School of Comprehensive Scientific Research, \\ Prefectural University of Hiroshima, Japan \\ ${ }^{3}$ Department of Community, Family, and Geriatric Nursing, Faculty of Nursing, \\ University of Jember, Indonesia
}

Received September 27, 2018 and accepted May 10, 2019

Published online in J-STAGE June 29, 2019

\begin{abstract}
This study aimed to investigate factors related to presenteeism among Chinese workers residing in Japan by assessing their mental state and health-promoting lifestyles. An anonymous, self-reported questionnaire was administered to 450 Chinese workers living in Hiroshima Prefecture, of whom, 313 completed it in its entirety. Results showed that $40.6 \%$ reported suffering from depression (Center for Epidemiologic Studies Depression Scale, CES-D). Sociodemographic characteristics such as being female, having a lower educational background, being widowed/divorced, having fewer years of residence, fluency in basic-level Japanese, being employed part-time, being an engineer, and workplace environment (having no health education in the workplace) increased the likelihood of depression. Path analysis indicated that marital status (being married) was negatively associated with presenteeism on the Work Limitations Questionnaire-Chinese version via work-related stress. There was a positive correlation between work-related stress and presenteeism through mental health (CES-D). Health-promoting lifestyles (Health-Promoting Lifestyle Profile II) showed a negative correlation with presenteeism, via work-related stress and mental health. Furthermore, health-promoting lifestyles showed a direct negative association with presenteeism. Thus, health education that emphasizes mental health was a significant factor for improving presenteeism. Furthermore, the provision of health education shortly after Chinese workers had arrived in Japan is important.
\end{abstract}

Key words: Labor productivity, Health-promoting lifestyle, Mental health, Chinese, Presenteeism, Work Limitations Questionnaire, Center for Epidemiologic Studies Depression Scale

\section{Introduction}

*To whom correspondence should be addressed.

E-mail: d183247@hiroshima-u.ac.jp

(C)2020 National Institute of Occupational Safety and Health
The Japanese government accepts foreign workers due to shortages in the workforce. At the end of October 2018 there were 1.46 million foreign workers in the country, 
which represented a $14.2 \%$ increase over the previous 12 months. Of these employees, workers from the People's Republic of China (hereinafter, "China") were the most numerous, accounting for $26.6 \%$ of the entire foreign labor force ${ }^{1)}$. Foreign workers are at high risk of exposure to occupational issues, injuries and disease ${ }^{2)}$. Maintaining safety and health standards for foreign workers is important in order to improve their productivity ${ }^{3)}$.

Recently, health-related productivity has been the focus of research in Japan and throughout the world, and a degradation in these standards can be measured using absenteeism and presenteeism ${ }^{4}$. Previous studies reported that mental-health conditions have the greatest impact on a decline in health-related productivity ${ }^{5-8)}$, with increased stress in the workplace leading to increased presenteeism $^{9,10)}$. Presenteeism refers to an employee who goes to work in spite of poor health, and such an employee can be considered as someone who is somewhere between fully engaged in his/her job and absent from work. Researchers have demonstrated an association between presenteeism and declining productivity, which contributes towards losses for the company, as well as leading to a degradation in the health conditions of employees along with a high risk of suicide ${ }^{11)}$. Therefore, it is important to understand the factors that influence presenteeism in the workplace and its influence on productivity, as well as the more studied construct of absenteeism.

Workplace conditions can affect the mental health of foreign workers ${ }^{12)}$. In terms of type of occupation, previous reports have shown that skilled professions have the highest rates of presenteeism, followed by the manufacturing industry, which hires the largest number of foreign workers ${ }^{13)}$. Furthermore, it has been reported that individuals who come to Japan for the purpose of work/ training tend to be more likely to suffer from depression than those who arrive for other purposes ${ }^{14)}$. There have also been reports that foreign workers feel a greater psychological burden at work and experience more stress due to interpersonal relationships in the workplace than Japanese workers ${ }^{15)}$.

Factors that cause stress for foreign workers include health-related activities held in a foreign country, their reasons for moving to Japan, ability to communicate in the native language, exposure to different cultures and values, workplace environment, and living environment ${ }^{16)}$. Furthermore, there have been reports that workplace conditions can increase the risk of foreign workers suffering from mental-health problems ${ }^{12)}$ and work-related accidents ${ }^{17)}$.
Participating in health-promoting programs can help address these issues and improve work productivity ${ }^{18)}$; however, according to occupational health research conducted on immigrant workers in Japanese workplaces, only $62.5 \%$ of such workplaces implement health and safety educa$\operatorname{tion}^{19)}$. On the others hand, various occupational health and safety services have been implemented among foreign workers living in Japan but not on a level comparable with Japanese workers ${ }^{3)}$. Meanwhile, it is necessary to maintain the health and safety status of foreign workers through health checks and follow-up, and providing education on how to stay healthy while working as stated in the technical guidelines for industrial health and safety in Japan ${ }^{3}$.

Previous studies have only focused on job-related stress among highly-skilled foreign workers in Japan ${ }^{15)}$ and depression among Chinese factory workers ${ }^{20)}$. However, no studies to date have revealed the mental health status, the issue of presenteeism among Chinese workers living in Japan, nor managed to identify any relationship between personal characteristics, workplace environment, the mental health status, and presenteeism. In an effort to fill this gap, we reveal the mental health status of Chinese workers and examine how personal characteristics including physical conditions might affect the mental health status and presenteeism, and investigate the relationships between factors described above. In addition, we attempted to identify how health-promoting lifestyles can improve mental health and reduce presenteeism among Chinese workers, who account for the majority of foreign workers in Japan (Fig. 1).

\section{Methods}

\section{Subjects}

The subjects for this study were Chinese workers aged $20 \mathrm{yr}$ or above, residing in Hiroshima Prefecture, Japan. The eligibility criteria were being of Chinese nationality and employed, regardless of employment format or job type; the duration of the individual's stay in Japan was irrelevant. The exclusion criteria were individuals who could not complete a Chinese survey form by themselves, and those who were diagnosed as having dementia.

\section{Study design and recruitment}

A cross-sectional study using a self-administered questionnaire was conducted. Between July and October 2017 , one of the present researchers visited 25 Japaneselanguage schools within Hiroshima Prefecture that were attended by Chinese people. Here, surveys were distrib- 


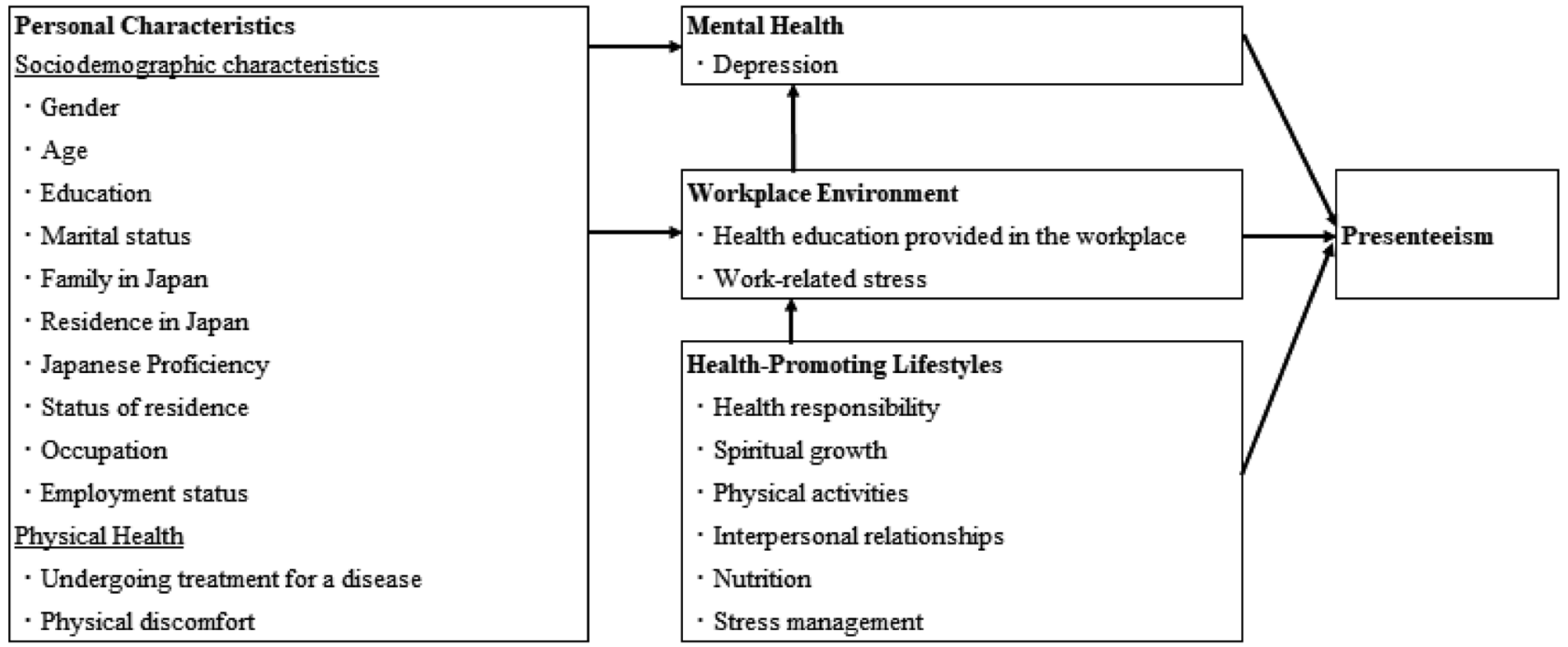

Fig.1. Research framework of this study.

uted to eligible Chinese workers who attended the classes; in addition, some of those present at the classes introduced the researcher to other Chinese workers, and these newlyintroduced workers were also invited to participate. The researcher distributed the survey after confirming that the participants had fulfilled the eligibility criteria. The subjects were asked to place their completed survey in a collection box installed in the classroom; additionally, a stamped and addressed envelope was given to the subjects to allow them to return the survey by mail if they wished to do so.

This distribution method was employed because the researchers were unable to obtain a list of Chinese people residing in Japan from governmental agencies and because they encountered difficulties ascertaining the number of Chinese workers employed at specific workplaces.

Altogether, the surveys were distributed to 450 subjects, and completed surveys were collected from 348 (retrieval rate: $77.3 \%$ ). Of these, the responses of 313 subjects (those who answered all items) were used for analysis (effective response rate: $69.4 \%$ ).

This study was approved by the epidemiological research ethics committee of Hiroshima University (approval number: E-831). The study was conducted by maintaining subjects' anonymity. Subjects were given both an oral and written briefing regarding the purpose and scope of the study, the random recruitment of subjects, confidentiality of data, and methods employed for protecting subjects' privacy after publication of study data. Submitting the questionnaire was regarded as having provided consent.

\section{Data collection and measurements}

Sociodemographic characteristics and workplace environment

Regarding the respondents' characteristics, the following data were obtained: gender, age group, educational background, marital status, presence of family members in Japan, duration and status of residence ("student", "dependent", "permanent resident/spouse of a Japanese national", "technical intern in training", and "other"), Japanese proficiency, status of residence, occupation ("service", "engineering", "manufacturing", "clerical work", and "other"), employment type, whether they were receiving treatment for a disease, and whether they were experiencing any physical discomfort. As for workplace environment, the subjects were asked about the availability of health education in the workplace (existence of specific health guidance and education) and whether they participated in it, and to rate the level of stress they feel in the workplace using a Likert scale ranging from 0 (no stress) to 10 (the maximum amount of stress).

Residence status was categorized following the categorization used by the Ministry of Health, Labour and Welfare $^{21)}$, while occupation was categorized following the Standard Occupational Classification for Japan ${ }^{22)}$. "Skilled" referred to a specialized/skilled work practitioner, while "manufacturing" referred to a manufacturing process worker.

\section{Presenteeism}

Presenteeism was measured using the Work Limitations Questionnaire-Chinese version (WLQ-C: Chinese 
edition $^{23)}$. WLQ-C is a self-administered questionnaire comprising 25 questions across four subscales: time management (five items), physical demands (six items), mental-interpersonal demands (nine items), and output demands (five items). The WLQ-C question items focus on instances over the past two weeks when respondents could not complete their work due to health problems. Responses are given using a five-point scale comprising the following: "it constantly caused a hindrance", "it frequently caused a hindrance", "it sometimes caused a hindrance", "it caused a slight hindrance", and "it did not hinder me at all"; furthermore, the response "this does not apply to my job" was also available. Each participant's total score for each subscale is converted into a value ranging from 0 to 100 ; then, using these scores, the rate of deterioration of work productivity is calculated using an algorithm. Higher numbers indicate a lower level of work-productivity loss.

\section{Mental-health status}

Mental-health status was measured using the Center for Epidemiological Studies-Depression scale (CES-D Chinese edition $)^{24)}$. This scale is the Chinese edition of a depression scale that is widely accepted to be effective for screening depression through measuring mental-health state. For each item, respondents give a value ranging from $0-3$, depending on the frequency by which they experienced the event in question over the previous week $(0=$ "rarely" or "not at all", $1=$ "some" or "some of the time", $2=$ "moderately" or "much of the time", $3=$ "most" or "almost all of the time"). There are 20 items in total. Scores range from 0 to 60 , with individuals scoring 15 or below being evaluated as not having depressive symptoms, those scoring 16-19 as showing the potential of having depression, and those scoring over 20 points as exhibiting depressive symptoms.

\section{Health-promoting lifestyle}

The Health-Promoting Lifestyle Profile II (HPLP-II R: Chinese edition) ${ }^{25)}$ was used to measure the respondents' health-promoting lifestyles. This scale is comprised of 40 items, categorized into six subscales: health responsibility; spiritual growth; physical activity; interpersonal relations; nutrition; and stress management. It is scored using a four-point Likert scale, with the responses being "never", "rarely", "sometimes", and "always". Once the scale has been completed, the mean score for all 40 items is calculated, with higher scores indicating that the respondent leads a healthy lifestyle.

\section{Statistical analysis}

Descriptive statistics were used to analyze personal characteristics and workplace environment, and mental health status. Cronbach's $\alpha$ coefficients to confirm the reliability of each scale and correlations were calculated. Additionally, Pearson's correlations between the WLQ-C, CES-D, HPLP-IIR, and Work stress were determined.

Next, in order to clarify the relationship between presenteeism and other independent variables aside from WLQ-C, a multiple regression analysis (stepwise methods) was conducted in order to clarify the relationship between presenteeism and studied parameters (excluding WLQ-C). Furthermore, based on the results obtained here, we created a model for the overall relationships among all factors, and we examined to what degree this matched with our data via the path-analysis method.

For statistical analysis, the statistical software SPSS (Ver. 21.0; manufactured by IBM) and AMOS (Ver. 22.0: manufactured by IBM) was used, with the significance level set at under $5 \%$.

\section{Results}

Subjects' characteristics, workplace environment, and mental health

Table 1 illustrates the subjects' characteristics and workplace environment. Of the 313 subjects who provided valid responses, most were women $(n=196,62.6 \%)$, the most common age group was $20 \mathrm{~s}(\mathrm{n}=163 ; 52.1 \%)$, and the majority were university graduates or higher $(n=149$; 47.6\%). Regarding marital status, "married" was the most common response $(\mathrm{n}=189,60.4 \%)$, and 186 respondents (59.4\%) had family members in Japan. The most common duration of residence in Japan was $1-3 \mathrm{yr}$ ( $\mathrm{n}=93 ; 29.7 \%$ ). Approximately $40 \%$ reported experiencing problems in their everyday lives as a result of their Japanese proficiency. The most common residence statuses were permanent resident and being a spouse to a Japanese national $(\mathrm{n}=113$; $36.1 \%$ ), followed by student ( $\mathrm{n}=74 ; 23.6 \%$ ), and technical intern $(\mathrm{n}=62 ; 19.8 \%)$. The service industry $(\mathrm{n}=103 ; 32.9 \%)$ and manufacturing industry $(\mathrm{n}=91 ; 29.1 \%)$ accounted for over $60 \%$ of the respondents' occupations. The most common employment type was part-time employment $(n=107$; $34.2 \%)$, followed by fixed term and contract worker $(\mathrm{n}=87$; $27.8 \%)$, and full-time employment $(\mathrm{n}=55 ; 17.6 \%)$. As for currently undergoing treatment for a disease, the majority of the respondents did not currently have any diseases $(\mathrm{n}=293 ; 93.6 \%)$ and did not suffer from physical discomfort $(\mathrm{n}=273 ; 87.2 \%)$. Meanwhile, 121 (38.7\%) respondents 
Table 1. Characteristics and Work Environment of the Study subjects $(\mathrm{N}=313)$

\begin{tabular}{|c|c|c|c|c|c|}
\hline \multirow{2}{*}{ N (\%) } & & & \multicolumn{2}{|c|}{ Mental health (Depression) with CES-D } & \multirow{2}{*}{ Mean (SD) } \\
\hline & & & $(16-19)$ & $\geq 20$ & \\
\hline \multicolumn{6}{|l|}{ Gender } \\
\hline Male & 117 & 37.4 & $14(12.0)$ & $25(21.4)$ & $11.30(10.37)$ \\
\hline Female & 196 & 62.6 & $16(8.2)$ & $72(36.7)$ & $14.24(11.37)$ \\
\hline \multicolumn{6}{|l|}{ Age group (yr) } \\
\hline $20-29$ & 163 & 52.1 & $18(11.0)$ & $52(31.9)$ & $13.82(11.37)$ \\
\hline $30-39$ & 95 & 30.4 & $7(7.4)$ & $26(27.4)$ & $11.32(9.55)$ \\
\hline $40-49$ & 35 & 11.2 & $3(8.6)$ & $14(40.0)$ & $15.23(13.75)$ \\
\hline $50-59$ & 18 & 5.8 & $1(5.6)$ & $5(27.8)$ & $12.56(10.27)$ \\
\hline$\geq 60$ & 2 & 0.6 & $1(50.0)$ & $0(0.0)$ & $14.00(4.24)$ \\
\hline \multicolumn{6}{|l|}{ Education } \\
\hline Middle (Junior High) School & 61 & 19.5 & $4(6.6)$ & $23(37.7)$ & 14.07 (11.39) \\
\hline High school & 103 & 32.9 & $5(4.9)$ & $40(38.8)$ & $14.08(11.87)$ \\
\hline$\geq$ College & 149 & 47.6 & $21(14.1)$ & $34(22.8)$ & $12.12(10.35)$ \\
\hline \multicolumn{6}{|l|}{ Marital status } \\
\hline Single & 112 & 35.8 & 13 (11.6) & $39(34.8)$ & $14.67(11.64)$ \\
\hline Married & 189 & 60.4 & $16(8.5)$ & $52(27.5)$ & $11.80(10.30)$ \\
\hline Widower/Divorced & 12 & 3.8 & $1(8.3)$ & $6(50.0)$ & $20.00(14.03)$ \\
\hline \multicolumn{6}{|l|}{ Family in Japan } \\
\hline Yes & 186 & 59.4 & $16(8.6)$ & $63(33.9)$ & $13.44(11.55)$ \\
\hline No & 127 & 40.6 & $14(11.0)$ & $34(26.8)$ & $12.72(10.39)$ \\
\hline \multicolumn{6}{|l|}{ Residence in Japan (yr) } \\
\hline$<1$ & 48 & 15.3 & $7(14.6)$ & $10(20.8)$ & $11.77(9.97)$ \\
\hline$\geq 1$ and $<3$ & 93 & 29.7 & $3(3.2)$ & $39(41.9)$ & $14.33(10.66)$ \\
\hline$\geq 3$ and $<5$ & 64 & 20.4 & $10(15.6)$ & $16(25.0)$ & $12.69(11.71)$ \\
\hline$\geq 5$ and $<10$ & 47 & 15 & $4(8.5)$ & $13(27.7)$ & $11.57(11.18)$ \\
\hline$\geq 10$ & 61 & 19.5 & $6(9.8)$ & $19(31.1)$ & $14.10(11.82)$ \\
\hline \multicolumn{6}{|l|}{ Japanese proficiency } \\
\hline Almost none/Some basic Japanese & 18 & 5.8 & $1(5.6)$ & $6(33.3)$ & $12.17(11.50)$ \\
\hline Understand basic Japanese & 99 & 31.6 & $6(6.1)$ & $43(43.4)$ & $15.30(11.46)$ \\
\hline Use in everyday situation & 114 & 36.4 & $12(10.5)$ & $32(28.1)$ & $13.30(10.67)$ \\
\hline Use in a variety of circumstances & 82 & 26.8 & $11(13.4)$ & $16(19.5)$ & $10.55(10.72)$ \\
\hline \multicolumn{6}{|l|}{ Status of residence } \\
\hline Student & 74 & 23.6 & $11(14.9)$ & $25(33.8)$ & $15.68(11.52)$ \\
\hline Dependent & 25 & 8 & $0(0.0)$ & $13(52.0)$ & $15.48(9.90)$ \\
\hline Permanent resident/Spouse of Japanese national & 113 & 36.1 & $10(8.8)$ & $28(24.8)$ & $11.54(11.05)$ \\
\hline Technical intern training & 62 & 19.8 & $3(4.8)$ & $25(40.3)$ & $14.21(10.74)$ \\
\hline Others & 39 & 12.5 & $6(15.4)$ & $6(15.4)$ & $9.74(10.44)$ \\
\hline \multicolumn{6}{|l|}{ Occupation } \\
\hline Service & 103 & 32.9 & $15(14.6)$ & $37(35.9)$ & $15.09(10.77)$ \\
\hline Engineer & 57 & 18.2 & $3(5.3)$ & $28(49.1)$ & $15.74(11.72)$ \\
\hline Manufacturing & 91 & 29.1 & $9(9.9)$ & $13(14.3)$ & $10.04(10.56)$ \\
\hline Clerical work & 4 & 1.3 & $1(25.0)$ & $1(25.0)$ & $10.00(10.98)$ \\
\hline Others & 57 & 18.2 & $2(3.5)$ & $18(31.6)$ & $12.19(10.89)$ \\
\hline \multicolumn{6}{|l|}{ Employment status } \\
\hline Full-time & 55 & 17.6 & $7(12.7)$ & $15(27.3)$ & $10.91(10.03)$ \\
\hline Part-time & 107 & 34.2 & $11(10.3)$ & $38(35.5)$ & $14.30(11.62)$ \\
\hline Fixed term and contract & 87 & 27.8 & $8(9.2)$ & $26(29.9)$ & $13.64(11.40)$ \\
\hline Others & 64 & 20.4 & $4(6.3)$ & $18(28.1)$ & $12.45(10.49)$ \\
\hline
\end{tabular}


Table 1 continued.

\begin{tabular}{|c|c|c|c|c|c|}
\hline \multirow{2}{*}{ N (\%) } & & & \multicolumn{2}{|c|}{ Mental health (Depression) with CES-D } & \multirow{2}{*}{ Mean (SD) } \\
\hline & & & $(16-19)$ & $\geq 20$ & \\
\hline \multicolumn{6}{|c|}{ Undergoing treatment for a disease } \\
\hline No & 293 & 93.6 & $28(9.6)$ & $86(29.4)$ & $12.77(10.88)$ \\
\hline Yes & 20 & 6.4 & $2(10.0)$ & $11(55.0)$ & $18.65(12.72)$ \\
\hline \multicolumn{6}{|c|}{ Physical discomfort } \\
\hline No & 273 & 87.2 & $27(9.9)$ & $80(29.3)$ & $12.63(10.99)$ \\
\hline Yes & 40 & 12.8 & $3(7.5)$ & $17(42.5)$ & $16.65(11.21)$ \\
\hline \multicolumn{6}{|c|}{ Health education provided in the workplace } \\
\hline No & 192 & 61.3 & $22(11.5)$ & $73(38.0)$ & $14.88(10.62)$ \\
\hline Yes & 121 & 38.7 & $8(6.6)$ & $24(19.8)$ & $10.39(11.28)$ \\
\hline Not attended & 39 & 32.2 & $2(5.1)$ & $10(25.6)$ & $12.18(11.83)$ \\
\hline Attended & 78 & 64.5 & $6(7.7)$ & $14(17.9)$ & $9.83(11.14)$ \\
\hline
\end{tabular}

CES-D: Center for Epidemiological Studies-Depression scale; SD: Standard deviation.

Table 2. Descriptive statistics and correlation coefficients for WLQ-C, CES-D, HPLP-IIR, and Work-related stress (N=313)

\begin{tabular}{lcccc}
\hline & 1 & 2 & 3 & 4 \\
\hline 1-WLQ-C & -- & & & \\
2-CES-D & $0.63^{* *}$ & -- & - & -- \\
3-HPLP-IIR & $-0.39^{* *}$ & $-0.41^{* *}$ & $-0.28^{* *}$ & 4.37 \\
4-Work-related stress & $0.47^{* *}$ & $0.47^{* *}$ & 2.68 & 2.92 \\
Mean & 5.07 & 13.14 & 0.57 & 0.95 \\
SD & 4.18 & 11.08 & 0.95 & \\
Cronbach's $\alpha$ & 0.93 & & \\
\hline
\end{tabular}

$* * p<0.01$.

WLQ-C: Work Limitations Questionnaire-Chinese version; CES-D: Center for Epidemiological Studies-Depression scale; HPLP-IIR: Health-Promoting Lifestyle Profile II; SD: standard deviation.

reported that health education was conducted in their workplaces, of which 78 (64.5\%) reported having such an education.

In terms of depression, $30(9.6 \%)$ respondents were found to have depressive tendencies (scoring 16-19 points on the CES-D), and 97 (31.0\%) were found to suffer from depression (scoring 20 points or more). The characteristics of being female $(36.7 \%)$, in the 40 s age group $(40.0 \%)$, having a high-school education (38.8\%), being widowed/ divorced (50.0\%), living with families in Japan (33.9\%), residing in Japan for less than $3 \mathrm{yr}(41.9 \%)$, understanding basic Japanese (43.4\%), having a residence status as a dependent (52.0\%), being an engineer by occupation (49.1\%), being employed part-time (35.5\%), undergoing treatment for a disease $(55.0 \%)$, having physical discomfort (42.5\%), and being provided with no health education at a workplace (38.0\%) were associated with an increased likelihood of suffering from depression.

Confirmation of reliability and correlation coefficients of each scale

Table 2 indicates the mean value, standard deviation (SD), and Cronbach's $\alpha$ coefficient of respondents of each scale, $\alpha>0.9$ or more being obtained at all scales (total score). The mean value of CES-D was 13.14 ( $\mathrm{SD}=11.08)$. A moderate or higher correlation was observed in all scales $(p<0.01)$.

\section{Factors and characteristics that impact presenteeism}

Based on the results of multiple regression analysis (Table 3), a model for the causal relevance was created (Fig. 2). The final model that demonstrated the best fit with the data as a result of path analysis (AGFI $=0.98$, $\mathrm{CFI}=1.00$, RMSEA $<0.001$ ) showed that marital status (being married) had a negative correlation with presenteeism via work-related stress. Meanwhile, work-related stress showed a positive correlation with presenteeism via mental health. Health-promoting lifestyles showed a negative correlation with presenteeism via work-related stress and mental health. Furthermore, health-promoting lifestyles 
Table 3. Multiple linear regression analysis for presenteeism, mental-health status, work-related stress, and health-promoting lifestyles

\begin{tabular}{|c|c|c|c|c|c|}
\hline & \multicolumn{5}{|c|}{ WLQ-C } \\
\hline & \multirow{2}{*}{$\begin{array}{c}\text { Coeff } \\
(B)\end{array}$} & \multirow{2}{*}{$\begin{array}{c}\text { Std Coeff } \\
(\beta)\end{array}$} & \multirow{2}{*}{$\frac{\text { Significance }}{(p)}$} & \multicolumn{2}{|c|}{$95 \% \mathrm{CI}$ of $B$} \\
\hline & & & & Lower & Upper \\
\hline \multicolumn{6}{|l|}{ Independent variables } \\
\hline CES-D & 0.18 & 0.47 & $<0.001$ & 0.14 & 0.21 \\
\hline Work-related stress & 0.29 & 0.18 & $<0.001$ & 0.16 & 0.42 \\
\hline Residence in Japan (yr) & -0.33 & -0.11 & 0.013 & -0.59 & -0.07 \\
\hline $\begin{array}{l}\text { Status of residence (Permanent resident/Spouse of Japanese } \\
\text { national: } 0 \text {, Student: } 1 \text { ) }\end{array}$ & 1.31 & 0.13 & 0.002 & 0.48 & 2.15 \\
\hline Marital status (Single: 0, Widowed/ Divorced: 1 ) & -1.9 & -0.09 & 0.034 & -3.67 & -0.14 \\
\hline HPLP-IIR & -0.02 & -0.12 & 0.006 & -0.04 & -0.01 \\
\hline \multicolumn{6}{|l|}{$\mathrm{R}^{2}: 0.50$} \\
\hline & \multicolumn{5}{|c|}{ CES-D } \\
\hline & Coeff & Std Coeff & Significance & \multicolumn{2}{|c|}{$95 \% \mathrm{CI}$ of $\mathrm{B}$} \\
\hline & (B) & $(\beta)$ & $(p)$ & Lower & Upper \\
\hline \multicolumn{6}{|l|}{ Independent variables } \\
\hline Work-related stress & 1.61 & 0.43 & $<0.001$ & 1.25 & 1.97 \\
\hline HPLP-IIR & -0.14 & -0.29 & $<0.001$ & -0.19 & -0.1 \\
\hline Occupation (Manufacturing: 0, Service: 1) & 3.99 & 0.17 & $<0.001$ & 1.87 & 6.11 \\
\hline $\begin{array}{l}\text { Status of residence (Permanent resident/Spouse of Japanese } \\
\text { national: 0, Dependent: 1) }\end{array}$ & 4.11 & 0.1 & 0.28 & 0.44 & 7.78 \\
\hline Male: 0 , female: 1 & 3.73 & 0.16 & $<0.001$ & 1.67 & 5.81 \\
\hline \multicolumn{6}{|l|}{$\mathrm{R}^{2}: 0.37$} \\
\hline & \multicolumn{5}{|c|}{ Work-related stress } \\
\hline & Coeff & Std Coeff & Significance & \multicolumn{2}{|c|}{$95 \% \mathrm{CI}$ of $\mathrm{B}$} \\
\hline & $(B)$ & $(\beta)$ & $(p)$ & Lower & Upper \\
\hline \multicolumn{6}{|l|}{ Independent variables } \\
\hline HPLP-IIR & -0.03 & -0.25 & $<0.001$ & -0.05 & -0.02 \\
\hline Marital status (Single: 0, Married: 1) & -1.37 & -0.23 & $<0.001$ & -1.99 & -0.75 \\
\hline Disease being treated (No: 0 , Yes: 1 ) & 1.87 & 0.16 & 0.003 & 0.63 & 3.11 \\
\hline \multicolumn{6}{|l|}{$\mathrm{R}^{2}: 0.15$} \\
\hline & \multicolumn{5}{|c|}{ HPLP-IIR } \\
\hline & Coeff & Std Coeff & Significance & \multicolumn{2}{|c|}{$95 \% \mathrm{CI}$ of $B$} \\
\hline & $(B)$ & $(\beta)$ & $(p)$ & Lower & Upper \\
\hline \multicolumn{6}{|l|}{ Independent variables } \\
\hline Health education provided in the workplace (No: 0 , Yes: 1 ) & 9.69 & 0.21 & $<0.001$ & 4.7 & 14.69 \\
\hline Japanese proficiency & 5.31 & 0.21 & $<0.001$ & 2.55 & 8.06 \\
\hline $\mathrm{R}^{2}: 0.09$ & & & & & \\
\hline
\end{tabular}

CI: confidence interval; Coeff: coeffcient; Std Coeff: standard coefficient; $\mathrm{R}^{2}$ : coefficient of determination; WLQ-C: Work Limitations QuestionnaireChinese version; CES-D: Center for Epidemiological Studies-Depression scale; HPLP-IIR: Health-Promoting Lifestyle Profile II.

showed a direct negative correlation with presenteeism.

This model, including mental health, work-related stress, health-promoting lifestyles, and marital state (being married), was able to explain $44 \%$ of presenteeism.

\section{Discussion}

This research described mental health, presenteeism, and related factors among Chinese workers living in Japan. It was found that high rate of Chinese workers in Japan suffered from depression. Personal characteristics and workplace environment increased the likelihood of de- 


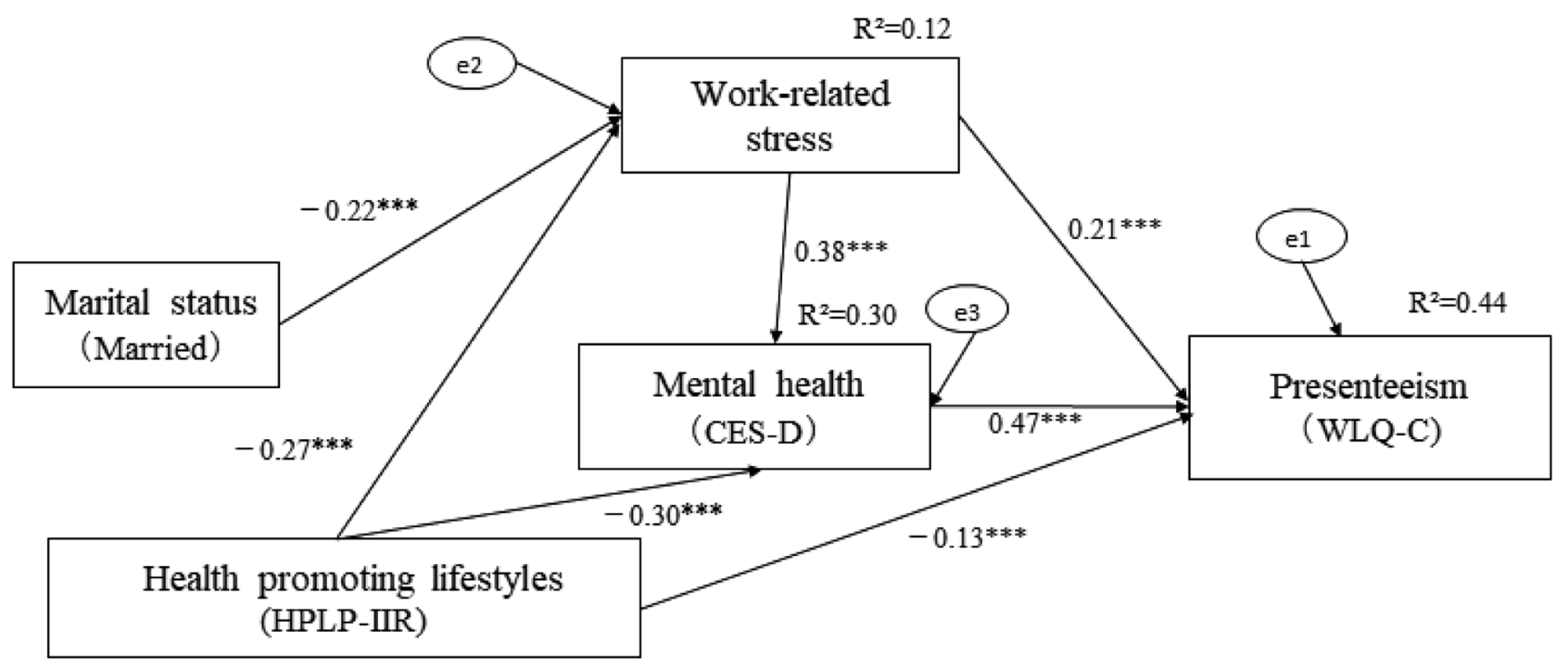

Fig. 2. Path analysis of variables associated with presenteeism. $\mathrm{N}=313, \chi^{2}=2.53, \mathrm{df}=3, p=0.47, \mathrm{AGFI}=0.98, \mathrm{CFI}=1.00$, RMSEA $<0.001,{ }^{* * *} p<0.001$.

pression among Chinese workers. Meanwhile, we found a positive correlation between mental health and presenteeism. Health-promoting lifestyles were significantly related to major factors such as work-related stress, mental health, and presenteeism. Path analysis showed that a health-promoting lifestyle negatively correlated with presenteeism, via work-related stress and mental health. Furthermore, health-promoting lifestyles showed a negative association with presenteeism.

\section{The mental health status of Chinese workers living in Japan}

The percentage of cases of depression among Chinese workers was $40.6 \%$. Overall, the results showed a similar prevalence ${ }^{16)}$ of depressive symptomatology and similar risks for depression that have been reported in previous studies, especially for those who were women ${ }^{26,27)}$, had low Japanese-language proficiency ${ }^{16)}$, and those who were receiving treatment for a disease, who were all at an elevated risk ${ }^{28}$.

By occupation, previous studies have demonstrated that the rates of depression in workers in the professional and manufacturing industry were higher than in other industries $^{13)}$; however, in this study, the engineering and service industries showed the highest percentage of individuals with depression out of all industries included in our analysis. The scores found in this study were higher than those previously reported among Japanese workers in the same industry ${ }^{29)}$. Regarding residence status, the depression scores were higher in students, family dependents, and technical interns, which may be attributed to lack of proficiency in the Japanese-language, which may have affected their employment prospects and financial status. Furthermore, some of those who were living with family also had a spouse who was a foreign student. A previous study reported that $74.8 \%$ of foreign students had a part-time job $^{30)}$, with restrictions about hours of employment. This situation could mean that the household has an insufficient income. Moreover, individuals may attempt to accommodate their part-time work by reducing their hours of sleep, leading to regular sleep deprivation, which in turn has a negative impact on depressive tendencies ${ }^{31)}$. As for technical interns, these individuals are not allowed to change the place of their internship. Being unable to switch from an existing work environment has been previously linked to great psychological stress ${ }^{32)}$.

Finally, those who received health education at the workplace had low depression scores. Health education has previously been found to reduce depression ${ }^{33)}$. Our results also indicated that health education appears to have a positive influence on mental health.

Relationship between mental health status, health-promoting lifestyles, and presenteeism

The path analysis showed that mental health had the strongest association with presenteeism and work-related stress also is related to presenteeism as described in Fig. 2. Furthermore, our results demonstrated that improving health-promoting lifestyles was related to improved mental health status, less stress at work, and improved 
presenteeism. These findings are similar to those reported in previous studies ${ }^{5-8,10,34-38)}$.

In this study only $38.7 \%$ answered that health education was provided in their workplace. According to the Industry Safety and Health Act, a workplace with 50 or more employees must appoint an industrial physician to oversee the health management of employees. However, businesses with less than 50 employees are not currently obliged to meet this requirement ${ }^{39)}$. Even though we did not ask about the number of employees in this study, the most common businesses that employ foreign workers are those with fewer than 30 employees ${ }^{40)}$. These results suggest that government agencies and employers of small businesses need to pay attention to health-promoting measures for foreign workers.

Although it was initially believed that the subjects' sociodemographic characteristics and workplace environment would significantly influence their mental health, and by extension, their presenteeism, the path analysis results showed that, among those personal characteristics, only marital status was indirectly associated with presenteeism through work-related stress. Moreover, personal characteristics did not influence depression directly. Previous studies that compared the mental health of the subjects before and after marriage have shown that mental health improves after marriage ${ }^{41)}$. This suggests that individuals who are married are more likely to receive support from family members than are single people, and this contributes to reduced work-related stress.

Thus, to improve presenteeism, there is a need to identify those foreign employees who are at a higher risk of suffering from this condition, pay attention to their mental status and level of work-related stress, and provide them with the necessary personal support and health education $^{42)}$. Assessing lifestyles and educating appropriate lifestyle behaviors for Chinese workers after they arrive in Japan are required to prevent a decline in their mental status.

\section{Study limitations}

The present study had a few limitations that are worth noting. Firstly, the study relied only on available subjects who attended Japanese language classes and their acquaintances, who met the eligibility criteria, as a result of the limitation we experienced with obtaining permission to acquire a list of Chinese people residing in Japan through government sources. It is, therefore, likely that this sample contained more part-time workers, which may not be representative of the general Chinese worker population in Japan. However, it became clear that health problems in this sample were associated with certain group characteristics. Additionally, the data used in this study were crosssectional and self-report measures, which limits our ability to make any causal determination about the patterns of association observed in this study. Future research, including longitudinal studies, would shed more light on the causal relationships between work-related stress and healthrelated problems among foreign workers.

\section{Conclusions}

We described the personal characteristics and workplace environment related to depressive tendencies and depression among Chinese workers residing in Japan. It was found that mental health status had a significant impact on presenteeism. Therefore, personal support and a healthrelated knowledge of the workplace environment might allow employers to mediate mental health among foreign workers. Furthermore, health-promoting lifestyles should be implemented in the workplace to improve mental health status and reduce presenteeism. Our findings suggest that providing health education in the workplace that enhances employees' health-promoting lifestyles should be enhanced to improve mental health status and reduce presenteeism among foreign workers. The provision of this type of education shortly after foreign workers had arrived in Japan is important.

\section{Funding}

This study did not receive funding in any form.

\section{Conflict of Interest}

The authors declare no conflict of interest.

\section{Acknowledgements}

We are grateful to the Chinese employees who responded to this survey. We would also like to express our gratitude to the volunteer staff who conducted the Japanese language classes and to Dr. Saori Kashima, Ph.D., an epidemiologist at Hiroshima University for her advice.

\section{References}

1) The Ministry of Health, Welfare, and Labour. Summary of the employment of foreign workers in the state (as of 
the end of October 2018). https://www.mhlw.go.jp/stf/ newpage_03337.html. Accessed February 1, 2019.

2) Ahonen EQ, Benavides FG, Benach J (2007) Immigrant populations, work and health-a systematic literature review. Scand J Environ Health 33, 96-104. [CrossRef]

3) Uchino A, Muto T, Muto S (2010) Occupational health and safety services for immigrant workers in Japanese workplaces. Ind Health 48, 231-5. [Medline] [CrossRef]

4) Mitchell RJ, Bates P (2011) Measuring health-related productivity loss. Popul Health Manag 14, 93-8. [Medline] [CrossRef]

5) Wada K, Moriyama M, Narai R, Tabara Y, Shikaguma R, Sato T, Aizawa Y (2007) The impact of chronic illness to work productivity in the Kanto District businesses. J Occup Health 49, 103-9.

6) Inaba Y (2014) The impact of female nurses' burning out onto work productivity. Jpn J Occup Med Traumatol 62, 173-8.

7) Lee YM (2010) Loss of productivity due to depression among Korean employees. J Occup Health 52, 389-94. [Medline] [CrossRef]

8) Taloyan M, Aronsson G, Leineweber C, Magnusson Hanson L, Alexanderson K, Westerlund H (2012) Sickness presenteeism predicts suboptimal self-rated health and sickness absence: a nationally representative study of the Swedish working population. PLoS One 7, e44721. [Medline] [CrossRef]

9) Ida H, Nakagawa K, Mitsuura S, Ishikawa S, Yagura N (2012) The development of work limitations questionnaire (WLQ-J) Japanese edition: Basic examination of its reliability and validity. J Occup Health 54, 101-7.

10) Aronsson G, Gustafsson K (2005) Sickness presenteeism: prevalence, attendance-pressure factors, and an outline of a model for research. J Occup Environ Med 47, 958-66. [Medline] [CrossRef]

11) Johns G (2010) Presenteeism in the workplace: a review and research agenda. J Organ Behav 31, 519-42. [CrossRef]

12) Hirano Y (2002) Study on socio-economic factors affecting depression of the foreign workers in Taiwan. Mem Kyushu U Sch Health Sci 29, 127-38.

13) Rost KM, Meng H, Xu S (2014) Work productivity loss from depression: evidence from an employer survey. BMC Health Serv Res 14, 597. [Medline] [CrossRef]

14) Hiroko H (2001) Research on the mental health of foreigners residing in Kyushu, Japan. Kyushu Univ Sch Health Sci Bull 28, 129-37.

15) Li JB (2015) The occupational stress and mental health of foreign workers residing in Japan with high skill/knowledge level: comparative examination with Japanese workers. Stress Sci Res 30, 90-101. [CrossRef]

16) Yamashita R, Hashimoto F, Shinnou K, Ueda T, Mori T, Yoshinaga J (2009) Mental health of foreign workers residing in Japan and its related factors. Collect Jpn Assoc Nurses Pap 39, 239-41.

17) Fujii H, Kusunose K, Yamanaka K (2013) Survey on foreign workers who received hospitalization due to occupational accident. Jpn J Occup Med Traumatol 61, 400-3.

18) Mitchell RJ, Ozminkowski RJ, Serxner S (2013) Improving employee productivity through improved health. J Occup Environ Med 55, 1142-8. [Medline] [CrossRef]

19) Uchino A, Muto T, Muto S (2010) Occupational health and safety services for immigrant workers in Japanese workplaces. Ind Health 48, 231-5. [Medline] [CrossRef]

20) Date Y, Abe Y, Aoyagi K, Ye Z, Takamura N, Tomita M, Osaki M, Honda S (2009) Depressive symptoms in Chinese factory workers in Nagasaki, Japan. Ind Health 47, 376-82. [Medline] [CrossRef]

21) The Ministry of Work, Health, and Labour: The categories of foreigners who work in Japan. www.mhlw.go.jp/stf/ seisakunitsuite/bunya/koyou_roudou/koyou/gaikokujin/ gaikokujin16/category_j.html. Accessed December 1, 2017.

22) The Ministry of Public Management Home Affairs, Posts and Telecommunications. Standard occupational classification in Japan (statistical standard set in December 2009). www.soumu.go.jp/main_content/000394337.pdf. Accessed February 3, 2017.

23) Dong XF, Liu YJ, Wang JX (2013) The development of the work limitations questionnaire, Chinese edition. Chin $\mathrm{J}$ Prac Nurs 29, 54-7.

24) Zhang MY (1993) Psychological evaluation scale book. 27-28, Hunan Science and Technology Press Corporation, Hunan.

25) Cao W, Guo Y, Ping W, Zheng JZ (2016) HPLP-II: The development and performance test of the health promotion Life Method Scale. Chin J Dis Control Pre 20, 286-9.

26) Ma BT (2007) The psychological health level of Chinese graduate students studying in Japan and its psychological/ social factor. Juntendo Med J 53, 200-10. [CrossRef]

27) Yokoda K, Yamamura M (2007) Research on the relevant factors to the depressive state of corporate employees: using SDS (self-administered depression scale) and periodic health checkup information. J Jpn Acad Health Sci 9, 217-24.

28) Lang C (2012) Factors related to the depressive state of elderly living in local communities in China: focusing on the impact to lifestyle, and mental/physical health. Jpn Psychol Res 2, 91-104.

29) Uchida M, Morita H (2018) Association between long work hours and depressive state: a pilot study of propensity score matched Japanese white-collar workers. Ind Health 56, 207-11. [Medline] [CrossRef]

30) The Japan Student Services Organization (JASSO) 2015 Field study on the lifestyles of privately funded foreign study students. http://www.jasso.go.jp/about/statistics/ryuj_ chosa/h27.html. Accessed December 17, 2017.

31) Brand S, Hermann B, Muheim F, Beck J, HolsboerTrachsler E (2008) Sleep patterns, work, and strain among young students in hospitality and tourism. Ind Health 46, 199-209. [Medline] [CrossRef] 
32) Yoshida M (2012) Current state and challenges of foreign skilled training system: research report by JITCO. Inst Int Relat Area Stud 36, 207-20.

33) Kamioka H, Nakamura Y, Yazaki T, Uebaba K, Mutoh Y, Okada S, Takahashi M (2004) Effectiveness of comprehensive health education combining hot spa bathing and lifestyle education in middle-aged and elderly women: randomized controlled trial of three-and six-month interventions. J Jpn Soc Balneol Climatol Phys Med 67, 202-14.

34) Onoi M, Si Q, Hayakawa K (2003) Physical/mental health level of Chinese residents in Japan and their lifestyle habits - based on the health needs field survey at city H. J Jpn Acad Community Health Nurs 5, 70-8.

35) Nagata T, Odagami K, Mori K (2014) Literature study on effect indices used in economic evaluation study in industrial health care activities. Jpn J Occup Med Traumatol 62, 370-5.

36) Lu L, Lin HY, Cooper CL (2013) Unhealthy and present: motives and consequences of the act of presenteeism among Taiwanese employees. J Occup Health Psychol 18, 406-16. [Medline] [CrossRef]

37) Danjo T, Okunaga J (2014) The relationship between sense of humor, presenteeism, and psychological health level of corporate employees. J Health Hum Ecol 80, 127-43.

38) Yang T, Zhu M, Xie X (2016) The determinants of presenteeism: a comprehensive investigation of stressrelated factors at work, health, and individual factors among the aging workforce. J Occup Health 58, 25-35. [Medline] [CrossRef]

39) The Ministry of Health, Welfare, and Labour. Disclosure of policies for examinations to ascertain degree of psychological burden, issue 2. www.mhlw.go.jp/ file/06-Seisakujouhou-11200000-Roudoukijunkyoku/ K151130K0040.pdf. Accessed February 1, 2017.

40) The Ministry of Health, Welfare, and Labour. Summary of the employment of foreign workers in the state (as of the end of October 2018).

41) Kubota H (1992) On the dissemination of social needs of mental health. Jpn J Psychosom Med 32, 307-14.

42) Yoshimura K, Kawakami N, Tsutsumi A, Inoue A, Kobayashi Y, Takeuchi F, Fukuda K (2013) Cost benefit analysis related to the primary prevention measure against mental health issues at Japanese workplace. J Occup Health 55, 11-24. 